\title{
The role of Ukrainian universities in the development of the global information society
}

Helen Kaikova*, Vagan Terziyan*, Seppo Puuronen**

* Software Department, Kharkov State Technical University

of Radioelectronics, 14 Lenina av., Kharkov, Ukraine

Phone: + 380572409 446;Fax: + 380572409113

Email:vagan@milab.kharkov.ua

** Department of Computer Science and Information Systems, University of Jyvaskyla, Finland

Phone: +358 14603 028; Fax: +35814603011

Email:sepi@jytko.jyu.fi

\begin{abstract}
This paper presents an observation of the positive experience obtained by Kharkov State Technical University in the area of education specialists for the development of an information society programme. Economic problems postponed the beginning of the information society programme in Ukraine. Nevertheless, Ukraine now has good possibilities to apply the best experience of western universities and speed up the process of transferring existing education to the European level. The paper also presents an analysis of the main trends that are taking place in that education. The paper uses the example of one of the leading Ukrainian technical universities to show the possible ways of positive changes in education in the framework of developing the national infrastructure of Ukraine. The examples show how the universities' sciences can be involved in large-scale transEuropean projects connected with problems of the global information society.
\end{abstract}




\section{INTRODUCTION}

Ukraine is a republic located in eastern Europe and it is a founding member of the Commonwealth of Independent States which, in December 1991, succeeded the USSR. With a total area of 603,700 square kilometres and a population of 51 million, Ukraine is now the second largest country in Europe (after Russia). Traditionally, Ukraine has had a high level of science and education. It has hundreds of universities and research institutes, and it has had quite a high level of universal and obligatory secondary education. Economic problems connected with disintegration of the states of the former USSR, and the Chernobyl catastrophe, postponed the initiation of the information society programme in Ukraine. The ongoing process of infrastructure development presupposes the solution of several problems connected with Ukraine's cultural and ethical peculiarities.

The information society programme has started in Ukraine. Its first official document, National Information Society Programme of Ukraine: Urgent Steps for the Period 1996-2,000, was signed in Kiev on October 30, 1995 by the head of the Agency for Information Society Problems who is attached to the president of the Ukraine. The document notes that Ukraine's current level of information society development is unsatisfactory (2-2.5\% when compared to western countries). It also includes the analysis of factors that are slowing down the process of successful development of the information society programme. The budget funds are planned to support:

- development of the national infrastructure;

- development of the national telecommunication system;

- information support development of the strategic directions of state interests, security and defence, and the social sphere.

The urgent steps are to develop the basis for standards and laws for the information society programme of Ukraine to be coordinated with international standards.

\section{THE ROLE OF EDUCATION IN THE INFORMATION SOCIETY OF UKRAINE}

We suppose that Ukrainian universities are able to make an essential input to the success of the information society programme through:

- education of a new type of specialist;

- cooperation with foreign universities to apply their best experiences in education;

- research on the strategic directions of the global information society;

- spreading the culture of the information society;

- developing exchange programmes for teachers and students;

- applying to European foundations to support joint projects.

To become the driving force in information society development, universities have to develop a lot in their own organization. We suppose that universities have to: 
- develop curriculums for computer science specialisms towards the best standards of European education and, at the same time, to keep up the best national traditions (for example, high levels of mathematical studies);

- pay more attention to language studies, cooperation, and negotiation skills to prepare for the possibility of wide exchange programmes;

- reconsider economic education in the universities by taking into account essential changes in national economics;

- develop the administrative structure of universities by applying evaluation techniques which are based on well-defined formal criteria;

- develop a system of funds distribution between and inside universities based on formal criteria (such as international conferences, papers, exchange programmes, doctoral theses, etc.);

- begin to use and to teach the use of legal software;

- find possibilities to install Internet and world wide web (WWW) facilities in the universities.

We consider that such changes in universities would help very much in developing the national infrastructure because of the following trends:

- cooperation between western and Ukrainian universities is growing. Western partners very often help with computers and with the organization of Internet connections. New modern courses introduced in Ukrainian universities will need facilities quite soon for teleeducation and teleconferences using the experience of the best lecturers from abroad. The requirements to apply to most European Community foundations mean it is necessary for universities to find new partners, and to establish new contacts. In such a situation, the infrastructure of Ukrainian higher education institutions will be developed quite fast;

- Ukrainian companies also need partners in western countries as well as new information technologies and good specialists. This means that contacts (including information exchange and electronic connection) will grow between those universities which are first involved in the European infrastructure and Ukrainian companies. Thus, Ukrainian companies are also expected to join the information society quite soon;

- scientific schools and research laboratories in Ukrainian universities already have results and experiences at their disposal in traditionally strong areas of national research that allow them to start some large-scale transEuropean projects together with western partners. This would affect very much the role of Ukraine in the European infrastructure and make it possible to earn essential funds for developing the information society programme of Ukraine.

Kharkov State Technical University of Radioelectronics (KHTURE) is one of the main universities educating specialists for the information society programme of Ukraine. KHTURE is the main institution to develop the information society programme in the most industrially and scientifically developed region, the northeast of Ukraine. The way that has been selected to improve the level of research and teaching activities in KHTURE is international cooperation and use of the experience of western universities. KHTURE's Faculty of Computer Sciences, with four specialities and twelve scientific schools in the area of computer science, is the leading faculty among Ukrainian universities. It develops curriculums, methods, and teaching aids that are applied to education in similar faculties of 
other technical universities. The research and educational laboratory, Metaintelligence, as part of KHTURE, has the main goal of participating in the development of the information society programme of Ukraine through international research and cooperation. Research topics of the laboratory include: knowledge and metaknowledge engineering; expert systems and multiple experts' problems in medicine; metamodels and metatools for information processing; mathematical methods and tools for biosignal analysis; metamathematics; computer-supported cooperative work; intelligent navigation in information systems; and human-computer interfaces.

In this paper, we show some experiences of KHTURE and the Metaintelligence Laboratory in developing education and research projects within the framework of the information society programme of Ukraine.

\section{DEVELOPING CURRICULUMS FOR COMPUTER SCIENCE SPECIALITIES}

The new curriculum, which has been developed at KHTURE in cooperation with the University of Jyvaskyla (Finland), includes the following main changes in comparison with traditional education in Ukraine (Kaikova et al., 1997):

- economic education has been extended twice, and its contents takes into account changes in Ukrainian economics towards a market orientation;

- mathematical education still has an essential role in the curriculum but it is also improved by developing the contents of some courses, for example, statistics, symbolic mathematics, and optimization methods;

- the curriculum includes a choice of one main speciality from two: artificial intelligence (AI) and information systems. The traditionally high quality AI education will be strengthened by additional up-to-date courses. The block of information systems courses has been totally renovated. It includes the following courses: information management; tools of personal and group work; object-oriented development of information systems; designing information systems; an advanced course on developing information systems; theoretical foundations of information systems; strategies for information technologies and business development; computer-supported cooperative work; and management strategies for information technology and its assessment;

- educational and industrial training, which was previously distributed throughout the whole 5-year education using summers, has now been reorganized into the system development project according to the best experiences of the Department of Computer Science and Information Systems of the University of Jyvaskyla;

- language education is extended almost twice and language studies are planned to be improved essentially by modern methods and by student exchange.

In the new curriculum, software systems are expected to be developed and used during many courses, for example: in general studies, small information and expert systems will be included; in economic studies, accounting and other economic systems will be used; in mathematical studies, training systems will be used; in artificial intelligence studies, some research prototypes will be produced, and most masters' theses will also include development of software that implements or 
verifies the ideas presented. Students will also be supposed to produce and present software in workshops, conferences, and exhibitions as previously.

Recent plans in the education area are to develop the university infrastructure and to organize distance education (lectures and summer schools) using the lecturers and telelearning facilities of the University of Jyvaskyla, which is the main foreign partner of KHTURE.

The authors are optimistically considering the perspectives of Ukrainian computer science education and its effect on the fast development of the information society in the Ukraine. They are also sure that cooperation between European partners (companies and universities) and Ukrainian universities seems to be beneficial to both sides.

\section{MULTIPLE EXPERTISE AND TELECONSULTING: TELEMEDICINE SYSTEMS DEVELOPMENT}

This project has been initiated by the Metaintelligence Laboratory together with students from KHTURE. It concerns the area of artificial intelligence applications in telemedicine. The project brings together the experience of Ukrainian researchers with computer-based intelligent medical systems, and the experience of Finnish researchers in the area of telecommunications, with their common experience in the area of multiple experts and, in addition, the expertise of German researchers in developing adaptive procedures of time series analysis and their application to problem settings in the biosignal analysis. The main goal of the project is to manage multiple expertise obtained from experts-physicians in different countries in order to develop a decision support medical system for broad earmarking based on telecommunication tools.

\section{Project objectives}

The project brings together the experience of Ukrainian researchers in computerbased intelligent medical systems (Dzundzjuk, 1989; Grebenyuk et al., 1994, 1995) and signal processing (Bondarecko et al., 1994; Terziyan and Tkachuk, 1995), with the experience of Finnish researchers in the area of telecommunications (a completely new, innovative telematic studio; local and remote multimedia groupware; computer-aided negotiation suites; telelearning environments; simulation; virtual reality, SUN and Silicon Graphics; Internet, and WWW services) and computer-supported cooperative work (Auromaki and Kovalainen, 1994a, 1994b), with their common experience in the area of multiple experts (Gerasin et al., 1994; Puuronen and Terziyan, 1996, 1997a, 1997b; Terziyan and Puuronen, 1997), and also with expertise of German researchers in the development of adaptive procedures of time series analysis and their application to problem settings in biosignal analysis (Griessbach and Schack, 1993; Griessbach and Witte, 1996; Schack et al., 1995).

The long and successful history of research cooperation between Ukrainian and Finnish Universities and some reasons to develop it further are presented in Kaikova and Terziyan (1997). The very important results obtained in the Institute of Biomedical Engineering and Medical Informatics (at the Technical University of 
Ilmenau) and the mutual interest in cooperation was the reason for including the German partner in the project.

\section{Research methods}

\section{Multiple experts voting-type technique}

The voting-type technique to manage knowledge obtained from multiple sources was proposed by Professor S. Puuronen (of the University of Jyvaskyla) and Professor V. Terziyan (from Kharkov State Technical University of Radioelectronics) (Gerasin et al., 1990; Puuronen and Terziyan, 1996, 1997a)

The technique is based on the derivation of the most supported opinion of the group of experts and its further refinement using a multilevel structure of knowledge sources or concepts.

The final statement (diagnosis) obtained as a result of the refinement process takes into account the opinions of all the experts according to their area of competence and the level of their expertise.

\section{Metaclassification technique with multiple statistical methods}

The first version of an intelligent system for statistical data processing MetaHuman-96 (MH96) was developed by researchers from the Metaintelligence Laboratory (at the Kharkov State Technical University of Radioelectronics) for the decision of medical diagnostics problems (Dzundzjuk et al., 1989; Grebenyuk et $a l ., 1994,1995)$. The problem of medical diagnostics was solved with the help of modern methods of discriminant and regressional analysis using information from training sets. MH96 contains the metamethod to support a user's decision-making about choice of method for a specific problem in medical diagnostics. The metamethod advises a user on the selection of one of the methods available in the system or offers a combination of them. The system allows the management of various medical databases (the user is allowed to configure structures of databases) and, using these data, the making of an analysis of a new object of diagnostics.

\section{Adaptive procedures for biosignal analysis}

The researchers from the Institute of Biomedical Engineering and Medical Informatics (at the Technical University of Ilmenau) led by Professor G. Griessbach are focused on the development of adaptive procedures of time series analysis and their application to problem settings in biosignal analysis. In the computer-aided analysis of biosignals, adaptive time series analysis methods are gaining more and more in importance (Griessbach and Schack, 1993). Due to their recursive proceeding, they permit an online evaluation of the time series and, due to their adaptive properties, a quick adaptation to changes occurring in the time series. In addition, they are robust against the great variety. of signal structures, thus representing an algorithmic initial approximation equally for deterministic signals with trend and transient signals. The recursive consistent estimate functions for parameters of stochastic processes are the mathematical background to the adaptive procedures.

Dynamic methods in the spectral domain are necessary to analyze biological signals because of the frequently nonstationary character of the signals. At present, not only the development of other adaptive parameters (e.g., adaptive recursive test 
statistics) is being investigated but also their mathematical-algorithmic properties. In addition, they are implemented by means of object-oriented technologies (Griessbach and Witte, 1996). An adaptive procedure was proposed for fitting timedependent models to nonstationary signals which is suitable for online calculations (Schack et al., 1995).

The essential role in developing telemedicine projects belongs to students of KHTURE who are already well educated in developing large software systems. Installation of such teleconsulting centres in Ukraine, first of all, helps persons who have suffered the hard consequences of the Chernobyl catastrophe, and also gives them the possibility of using the experience of foreign experts.

\section{INTERNATIONAL TELECONSULTING CENTRE ON MATHEMATICAL EXPERTISE}

Another important positive tradition in research in countries of the former Soviet Union is the high level of results in the area of mathematics. Now, it is very important and useful to make all those results that have been obtained during the long history of the main mathematical schools in Russia and other eastern countries available to European and to world society. One example of a possible way to establish access to this mathematical expertise is discussed in this section. The example supposes that the profit gained from realizing such a possibility can be used by Russian and Ukrainian universities to develop their own infrastructures.

Modern technological processes consist of complicated movements of media in different phases and dynamic phase transitions on free surfaces: melting, solidification, evaporation, condensation, etc. Most of the current mathematical models of phase changes include only a part of the physical phenomena (for example, separate Stefan equations or separate Navier-Stokes equations). For many physical situations, it is very important to take into account interactions between different types of processes and media. The physical experiments in this area are very expensive and it is difficult to get the full information about any processes of interest. One can make inaccurate conclusions about the behaviour of the physical system. For this reason, the correct construction of the complete model, coupled with a system of equations for different processes and media with phase transitions, has a big and practical interest. Using the expert system, investigators can choose different mathematical models according to their needs:

- mathematical models of stationary flow and heat mass transfer with fixed or unknown boundaries between the phases;

- mathematical models of deformation and thermodynamic state of solid bodies with a boundary between solid and liquid phases;

- quasi-stationary mathematical models of phase change problems (the stationary Navier-Stokes and the constitutive equations for free solid part and nonstationary thermodynamic equations);

- nonstationary mathematical models of phase change problems (melting processes, the nonstationary Navier-Stokes and constitutive equations for free solid part and the nonstationary thermodynamic equations). 
Theoretical analyses of these mathematical models include the proofs of smoothness, uniqueness, and stability. Finite element method is used for the numerical analysis of phase change problems. Using this method one can get:

- numerical simulation of the stationary boundary problems for the NavierStokes equations, using the domain decomposition method, parallel algorithms, multi-resolution method, and grid refinement;

- numerical simulation of the initial boundary problems for the nonstationary Navier-Stokes equations for arbitrary domain shapes using the projection method, domain decomposition methods, and up winding schemes;

- numerical simulation of boundary value problems of a solid and a mixed medium in an arbitrary domain;

- numerical simulation for the coupled phase change problem.

In this project, the expert system will suggest to the investigators the models for the different phase change problems and their numerical simulation. The models will include thermodynamic and constitutive equations for each phase and physical natural conditions on the unknown boundary between the phases. The expected results are: using the expert system, the investigators can choose some of the mathematical models, test whether they are correct or not, and get a numerical simulation of the problem.

The International Teleconsulting Centre on Mathematical Expertise (TELEMATH) is planned for installation at the Laboratory of Scientific Computing of the University of Jyvaskyla. The TELEMATH Centre will sell services to a wide network of users all around the world. The structure of the TELEMATH Centre is presented in Figure 1.

The expert system of TELEMATH is intended to solve complex multiphase and multiinterface problems using knowledge of mathematical models and methods acquired from multiple experts-mathematicians.

The area of expertise covers the mechanics of the continuous media investigated by the variations of the finite element method, and also different mathematical models: reaction-diffusion; the heat conduction; the laminar and turbulence flows of viscous compressible and incompressible liquid and gas; deformation of the solid body with different reological laws; coupled with problems from the phase changes, free boundaries, and others.

TELEMATH learns by acquiring expertise from different experts through an intelligent expert interface using a special methodology of mathematical knowledge acquisition and representation or unique expert language for mathematical knowledge description. The expert system receives a problem from a user through the intelligent user interface, controls its correctness, selects a mathematical model, determines the region's geometry, initial conditions and boundary conditions, selects a method (the type of the finite element, the order of approximation, domain discretization, the way of solving the final system of equations), derives the solution and introduces it to a user. The system is able to organize a teledialogue with experts in cases when it cannot itself make a decision. It is also possible to expand the knowledge bases by new models and methods permanently obtained from the experts. The organization of the expert system, methodology of knowledge acquisition, language, classification technique, and interfaces are supposed to be easily reoriented to new groups of models and methods. 
Figure 1. Structure of teleconsulting centre on mathematical expertise

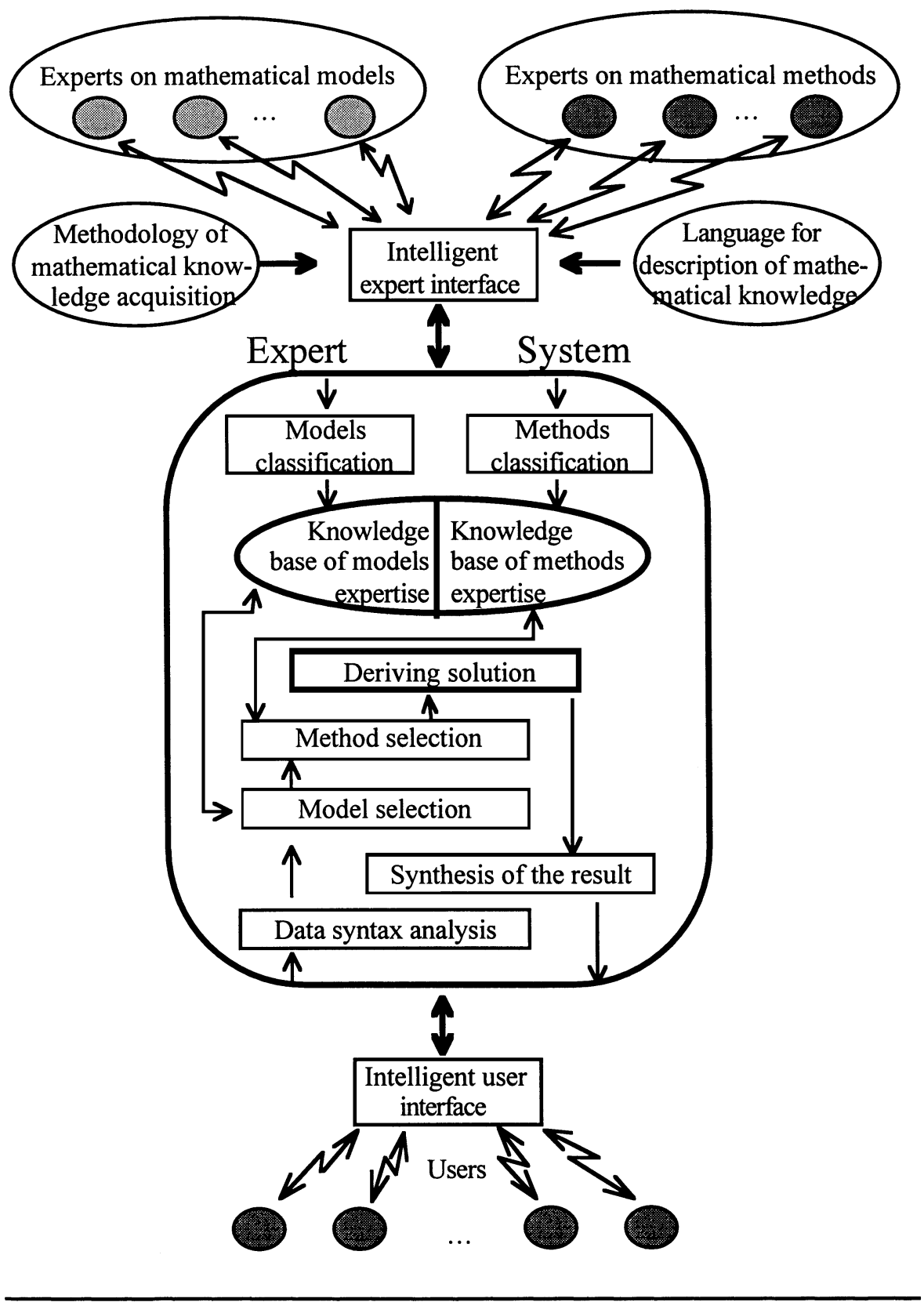


The project uses methods described elsewhere in this paper. The voting-type technique is used to manage knowledge obtained from different experts about the same mathematical object. It allows consensus among the experts concerning the description of a method or a model. The metaclassification technique is used to describe metamethods of selecting mathematical methods for a problem solution.

The project brings together the experience of Ukrainian researchers (from KHTURE) in the development of large computer-based intelligent systems, classification techniques, and multiple expertise, with the experience of Russian mathematicians (from St. Petersburg State Technical University and North-West Polytechnic Institute) in the area of mathematical models for the mechanics of continuous media and variations of the finite element method (Erunova and Rivkind, 1990, 1991), with the experience of Finnish researchers (from the University of Jyvaskyla) in the area of telecommunications and information technologies. The project is also supposed to use students widely to develop and to classify mathematical methods and to develop software.

\section{CONCLUSION}

This paper presents an observation of the positive experience gained by Kharkov State Technical University in the area of education specialists for the development of an information society programme. Economic problems have postponed the beginning of an information society programme in Ukraine. Nevertheless, Ukraine now has good possibilities to apply the best experience of western universities and speed up the process of transferring existing education to the European level. The paper also includes an analysis of the main trends that are taking place in that education. It presents an optimistic view of a future Ukrainian education and its essential role in the process of developing the information society in Ukraine. It uses the example of one of the leading Ukrainian technical universities to show possible ways of developing the organizational structure, education, and research activities in Ukrainian higher education institutions in order to participate in the development of the global information society.

\section{ACKNOWLEDGEMENTS}

We are grateful to the Centre for International Mobility and Ministry of Education of Finland whose support made it possible for Helen Kaikova and Vagan Terziyan to develop this research in Finland.

\section{REFERENCES}

1. Auramaki E., Kovalainen M., Computer Support for Sharing Expertise in Process Disturbances. In: Proceedings of XIII European Annual Conference on Human Decision Making and Manual Control, Espoo, Finland, 1994a.

2. Auramaki E., Kovalainen M., Computer Support for Sharing and Extending Expertise in Paper Process. In: CSCW94 International Workshop, North-Carolina, USA, 1994b. 
3. Bondarenko M., Terziyan V., Tkachuk A., Multilevel Models for Representation of QuasiPeriodical Temporal Patterns, In: Signal/Image Processing and Pattern Recognition, Second AllUkrainian International Conference, Kiev, Ukraine, 1994, pp. 76-80.

4. Dzundzjuk B., Terziyan V., Severina L., Development of Expert Health-Protection Systems Based on Discrete Mathematics, Bionics Problems Journal, 1989, 42, 104-109.

5. Erunova I.B., Rivkind V.J., Study of the Problem of Liquid Evaporation, Vestnic Leningrad University, 1991, 2 (8).

6. Erunova I.B., Rivkind V.J., On Estimates of the Rate of Convergence of Approximate Methods of Calculating the Flow of a Viscous Incompressible Fluid with a Free Surface in Domains with Corner Points, Soviet Mathematics Doklady, 1990, 313 (6).

7. Gerasin S., Kaikova H., Terziyan V., An Interval-Based Approach to Multiple Experts Opinions Processing: Successive Severance Method, Bionics Problems Journal, State University Publications, 1990, 44, 41-46.

8. Grebenyuk V., Kaikova H., Terziyan V., Fundamentals of Multilevel Pattern Recognition, In: Signal/Image Processing and Pattern Recognition, Second All-Ukrainian International Conference, Kiev, Ukraine, 1994, pp. 25-29.

9. Grebenyuk V., Kaikova H., Terziyan V., Multilevel Automatic Diagnostics Based on Models of Speech Behavior, In: Radioelectronics in Medicine Diagnostics, International Conference, Moscow, November 1995, pp. 131-139.

10. Griessbach, G., Schack, B., Adaptive Quantile Estimation and its Application in the Analysis of Biological Signals. Biometrical Journal, 1993, 35 (1).

11. Griessbach, G., Witte, H., Complex adaptive procedures for EEG monitoring, Kongreband zum 'Hans-Berger-Kongress 1996'.

12. Kaikova H., Terziyan V., Puuronen S., Software Engineering Education in the Ukraine: Towards Cooperation with Finnish Universities, In: Intern. Symposium on Software Engineering in Universities, Rovaniemi, Finland, March 1997, pp. 109-116.

13. Puuronen S., Terziyan V., Modelling Consensus Knowledge from Multiple Sources Based on Semantics of Concepts, In: Challenges of Design, ER96 International Conference on Conceptual Modelling, Cottbus, Germany, October 1996, pp. 133-146.

14. Puuronen S., Terziyan V., Voting-Type Technique of the Multiple Expert Knowledge Refinement, In: Sprague R. H., (Ed.), Proceedings of the Thirtieth Hawaii International Conference on System Sciences, Vol V, IEEE Computer Society Press, 1997a, pp. 287-296.

15. Puuronen S., Terziyan V., Colleague-Oriented Interpretation of Knowledge Acquired from Multiple Experts, In: PACES/SPICIS97 The Joint Pacific Asian Conf. on Expert Systems/Singapore Intern. Conf. on Intelligent Systems, Singapore, February 1997b.

16. Schack, B., Bareshova, E., Griessbach, G., Witte, H., Methods of Dynamic Spectral Analysis by Self-Exciting ARMA Models and their Application to Analysing Biosignals. Med. \& Biol. Eng. \& Computing, 1995, 33, 492-498.

17. Terziyan V., Puuronen S., Multilevel Context Representation Using Semantic Metanetwork, In: CONTEXT-97-Intern. and Interdisciplinary Conference on Modeling and Using Context, Rio de Janeiro, Brazil, February 1997, pp. 21-32.

18. Terziyan V., Tkachuk A., Multilevel Models for Speech-Based Diagnostics, In: RadioElectronics in Medicine Diagnostics, International Conference, Moscow, November 1995, pp.140-143. 